\title{
Comportamento dos amebócitos circulantes de moluscos planorbídeos frente ao parasitismo por larvas de Schistosoma mansoni, inoculação de tinta nanquim e fratura da concha*
}

\author{
Behavior of hemolymph amebocytes from planorbidae in the presence \\ of Schistosoma mansoni larvae parasitism, by inoculation of Indian ink \\ or fracture of the shell
}

\author{
Luciane de Seta, Luiz Augusto Magalhães, José Ferreira de Carvalho \\ Departamento de Parasitologia do Instituto de Biologia da Universidade Estadual de Campinas. \\ Campinas, SP - Brasil (L.S., L.A.M.), Departamento de Estatística do Instituto de Matemática, \\ Estatística e Ciências da Computação da Universidade Estadual de Campinas. Campinas, SP - \\ Brasil (J.F.C.)
}

\begin{abstract}
Resumo
Foi estudado o comportamento dos amebócitos circulantes de Biomphalaria glabrata e Biomphalaria tenagophila mediante à infecção pelo Schistosoma mansoni, à inoculação de tinta Nanquim e à fratura da concha. Foi realizada contagem diferencial de amebócitos na hemolinfa, dando-se ênfase aos tipos de células encontradas em cada amostra; avaliação histopatológica dos moluscos submetidos à exposição aos miracídios de S. mansoni; e análise da morfologia dos amebócitos através de microscopia de fase. Foi verificada correlação entre a variação do número de amebócitos circulantes e a reação tecidual. Em Biomphalaria tenagophila somente houve aumento do número de amebócitos estrelados quando os moluscos eram infectados por $S$. mansoni, o que sugere a especificidade da reação ao parasitismo. Comparando os resultados obtidos em B. glabrata e B. teganophila, concluiu-se que esses moluscos apresentam comportamentos amebocitários diferentes frente aos diversos estímulos utilizados.
\end{abstract}

Hemolinfa, citologia. Leucocitose. Biomphalaria, parasitologia.

\begin{abstract}
The behavior of the hemolymph amebocytes of Biomphalaria glabrata and Biomphalaria tenagophila was studied by means of the infection by the Schistosoma mansoni, using inoculation with Indian ink and fracture of the shell. A differencial count of the amebocytes in the hemolymph was made with special attention given to the types of cell found in each sample. Histopathological evaluation of the molluscs exposed to the Schistosoma mansoni miracidia and analyses of the amebocytes were made. Correlation between the variance of the number of hemolymph amebocytes and tissue reaction was also made. The
\end{abstract}

\footnotetext{
* Trabalho realizado com o auxílio da Fundação de Amparo à Pesquisa do Estado de São Paulo. Processo n 88/2336-2 e pelo Conselho Nacional de Desenvolvimento Científico e Tecnológico/CNPq. Processo n 405937/88-1.

Correspondência para/Correspondence to: Luiz Augusto Magalhães - Departamento de Parasitologia do Instituto de Biologia da Universidade Estadual de Campinas. Caixa Postal 6109 - 13083-970 Campinas, SP - Brasil. Fax: (019) 239-3124 E-mail: luiz@ correi-net.com.br. Edição subvencionada pela FAPESP. Processo 95/2290-6.

Recebido em 8.6.1995. Reapresentado em 6.2.1996. Aprovado em 27.2.1996.
} 
morphologycal study of amebocytes was carried out with the help of a phase microscope. An increase in granulocytes in Biomphalaria tenagophila occured only when the molluscs were infected by Schistosoma mansoni, which suggests the specificity of the reaction to the parasitism. Comparing the results obtained with B. glabrata and B. tenagophila it is concluded that these molluscs show different amebocitary behavior in the presence of the diverse stimuli used.

\section{Hemolymph, citology. Leukocytosis. Biomphalaria, parasitology.}

\section{INTRODUÇÃO}

Amebócitos ou hemócitos são células sangüíneas circulantes de invertebrados e de ação fundamental nas funções de defesa, tais como fagocitose ou encapsulação, liberação de substâncias citotóxicas, transporte de cálcio nas situações de reparo tecidual e na produção de fator coagulante da hemolinfa (Wegge $^{15}$, 1951; Cheng e Buttler ${ }^{5}$, 1979; Bayne e col. $^{3}, 1980$; Abdul Salam e Michelson ${ }^{1}$, 1980; Sminia e Van Der Knaap ${ }^{13}$, 1987; Amen e col. ${ }^{2}$, 1992).

Segundo Cheng e col. ${ }^{4}(1975)$ existem duas categorias de amebócitos na hemolinfa de Biomphalaria glabrata: os granulócitos e os hialinócitos, chamados, respectivamente, no presente trabalho de "estrelados" e "não estrelados", devido à sua aparência de célula estrelada, semelhante às células nervosas, ou sem prolongamentos citoplasmáticos observáveis ao microscópio óptico.

Não existem evidências concretas de que ocorram apenas duas ou mais populações de amebócitos circulantes ou que uma delas se transforme na outra. No entanto, sabe-se que os amebócitos denominados granulócitos são os responsáveis pela fagocitose de partículas estranhas. O número destas células bem como a taxa de fagocitose aumentam consideravelmente após a infecção pelo Schistosoma mansoni (Santana e col. ${ }^{12}, 1985$ ). Estes autores obtiveram uma taxa de fagocitose de $43 \%$ nos moluscos não submetidos à infecção e de 57 a $75 \%$ nos moluscos infectados. Amen e col. ${ }^{2}$ (1992), ao estudarem a modulação da atividade do sistema de defesa de Lymnaea stagnalis pelo Schistosoma trichobilharzia ocellata, observaram, nas primeiras horas após a infecção, uma ativação da resposta imune celular e humoral. $O$ desencadeamento da atividade de defesa associada ao plasma foi verificada entre 1,5 e 6 horas e à supressão entre 12 e 72 horas após a infecção. A ativação da resposta imune associada às células foi verificada entre 1,5 e 6 horas e também entre 8 e 10 semanas após a infecção. Discute-se a possibilidade de que as respostas encontradas sejam direcionadas às placas ciliadas perdidas pelos miracídios imediatamente após a penetração no molusco, do que pro- priamente ao parasita em desenvolvimento no esporocisto-mãe. Não se sabe ainda se os fatores humorais, que interferem na ativação e supressão da resposta de defesa, são derivados do parasita ou do molusco.

O presente trabalho teve como objetivos: a) Estudar a reação amebocitária "in vivo" frente a diferentes estímulos, comparando-a dentro da mesma espécie e entre duas espécies de moluscos (B. glabrata e B. tenagophila); b) verificar os tipos de células envolvidas em cada uma das situações; c) Verificar as alterações morfológicas dos amebócitos ocorridas no tempo, após a exposição aos miracídios e na ausência de exposição.

\section{MATERIAL E MÉTODO}

Foram utilizados moluscos Biomphalaria glabrata e B. tenagophila procedentes, respectivamente, de populações de Belo Horizonte, MG e de São José dos Campos, $\mathrm{SP}$, mantidos no moluscário. Esses moluscos foram infectados com as linhagens simpátricas BH e SJ (Paraense e Corrêa $\left.^{10}, 1963\right)$.

Cinco grupos experimentais foram formados com as duas espécies de planorbídeos:

1 - Moluscos não infectados (Grupo controle - 10 moluscos de cada espécie).

2 - Moluscos infectados com a linhagem simpátrica de $S$. mansoni (150 moluscos de cada espécie sendo 10 a cada intervalo de tempo).

3 - Moluscos inoculados com tinta Nanquim (130 moluscos de cada espécie sendo 10 a cada intervalo de tempo).

4 - Moluscos que sofreram injeção simulada (ausência de tinta Nanquim — 140 moluscos de cada espécie sendo 10 a cada intervalo de tempo).

5 - Moluscos com fratura da concha (230 moluscos de cada espécie sendo 10 a cada intervalo de tempo).

Para a avaliação cinética do número de amebócitos circulantes os moluscos eram expostos a 10 miracídios, e para o exame histopatológico a 100 miracídios por caramujo.

Utilizaram-se para a exposição aos miracídios, moluscos com 7 a 9 mm de diâmetro, recolhidos aleatoriamente.

Foram utilizados em cada tempo de 5 a 10 moluscos para a obtenção da hemolinfa, dependendo da taxa de mortalidade observada nos moluscos. 
A hemolinfa foi colhida na região céfalo-podal por punção rápida através da concha. A contagem diferencial de células foi feita em câmera de Neubauer e os amebócitos eram classificados como "estrelados" (granulócitos) e "não estrelados" (hialinócitos). Em todos os grupos a hemolinfa foi colhida aos primeiros 30 minutos e quantas vezes julgado necessário até completar 24 horas após a aplicação de cada um dos estímulos.

Para a inoculação de tinta Nanquim, os moluscos foram submetidos à anestesia em solução de mentol a $0,25 \%$ por um período de 4 horas. Posteriormente, eram inoculados na região céfalo-podal com 0,2 a 0.3 ul de tinta Nanquim através de seringa "carpule" de anestesia dentária. Foi utilizado processo idêntico para a inoculação simulada.

Constituiu-se o grupo 5 fraturando-se com estilete a concha de moluscos, próximo à região céfalo-podal, em condições de assepsia.

O exame histopatológico foi feito utilizando-se moluscos fixados em Bouin alcoólico. Após a fixação, era separada a região céfalo-podal até as proximidades do colar do manto. Posteriormente, o material era incluído em parafina. Foram realizados cortes seriados de 5 a 6 u de espessura e o material foi corado pelo tricrômico de Gomori. Os moluscos utilizados para o exame histológico foram sacrificados aos $30 \mathrm{~min}, 2 \mathrm{~h}, 10 \mathrm{~h}, 18 \mathrm{~h}$ e $24 \mathrm{~h}$ após à exposição à 100 miracídios.

O exame dos amebócitos era feito em microscopia de fase, à fresco, imediatamente após a colheita.

O experimento foi completamente aleatorizado. As respostas observadas para efeito de análise estatística foram o número de amebócitos estrelados e não estrelados. A análise estatística, para efeito comparativo, empregou modelo de análise de variância, com o fatorial tratamento x tempo, em cada espécie de molusco. Os dados das respostas foram previamente transformados para raiz quadrada, a fim de estabilizar as variâncias. Os efeitos foram comparados através de métodos de comparação múltipla. Todos os cálculos foram realizados com o sistema SAS $(6,03)$ em microcomputador tipo IBM PC-XT.

\section{RESULTADOS}

\section{Avaliação Cinética do Número de Amebócitos Circulantes}

Os dados referentes ao número médio de amebócitos circulantes encontrados nos diversos grupos experimentais de caramujos estão contidos nas Tabelas de 1 a 5 .

a) Moluscos infectados com a linhagem simpátrica de $S$. mansoni (Tabela 2).

Observou-se que os moluscos B. glabrata e $B$. tenagophila apresentaram perfis de variação do número de amebócitos circulantes totalmente diferentes. Em B. glabrata observou-se um perfil de variação semelhante à reação inflamatória de vertebrados, quando já no período de 30 min após à infecção pelo $S$. mansoni obteve-se um aumento significativo do total de amebócitos em relação ao grupo-controle (Tabela 1). No intervalo de $2 \mathrm{~h}$ após à infecção houve leve aumento do número de células e, após esse período, uma diminuição gradativa do número de células circulantes, voltando a atingir às 24 horas um número médio de células semelhante ao do grupocontrole. $\mathrm{O}$ aumento ocorrido entre $30 \mathrm{~min}$ e $2 \mathrm{~h}$ deveu-se exclusivamente aos amebócitos "não estrelados". Os amebócitos "estrelados" não apresentaram variação cinética significativa. Em B. tenagophila observou-se aumento tardio do número de amebócitos circulantes, se comparado aos resultados obtidos em B. glabrata submetidas à infecção. Este aumento ocorreu entre 14 e 18 h após a infecção, seguido de uma diminuição gradativa até as 24 h, quando assume valores semelhantes aos da média de amebócitos circulantes do grupo-controle. $\mathrm{O}$ aumento verificado deveu-se, exclusivamente, aos amebócitos "estrelados".

Tabela 1 - Número de amebócitos circulantes em moluscos do grupo 1 (controle- moluscos não infectados).

\begin{tabular}{|c|c|c|c|c|c|c|}
\hline \multirow[b]{2}{*}{ Molusco } & \multicolumn{3}{|c|}{ B. glabrata } & \multicolumn{3}{|c|}{ B. tenagophila } \\
\hline & $\begin{array}{l}\text { Amebócitos } \\
\text { totais }\end{array}$ & $\begin{array}{l}\text { Amebócitos } \\
\text { estrelados }\end{array}$ & $\begin{array}{l}\text { Amebócitos } \\
\text { não estrelados }\end{array}$ & $\begin{array}{l}\text { Amebócitos } \\
\text { totais }\end{array}$ & $\begin{array}{l}\text { Amebócitos } \\
\text { estrelados }\end{array}$ & $\begin{array}{c}\text { Amebócitos } \\
\text { não } \\
\text { estrelados }\end{array}$ \\
\hline 1 & 10 & 1 & 9 & 20 & 9 & 11 \\
\hline 2 & 11 & 1 & 10 & 21 & 8 & 13 \\
\hline 3 & 15 & 3 & 12 & 10 & 0 & 10 \\
\hline 4 & 14 & 6 & 8 & 21 & 13 & 8 \\
\hline 5 & 11 & 0 & 11 & 8 & 0 & 8 \\
\hline 6 & 16 & 2 & 14 & 9 & 2 & 7 \\
\hline 7 & 20 & 5 & 15 & 31 & 19 & 12 \\
\hline 8 & 14 & 8 & 6 & 11 & 5 & 6 \\
\hline 9 & 12 & 2 & 10 & - & - & - \\
\hline 10 & 9 & 4 & 5 & - & - & - \\
\hline Totais & 132 & 32 & 100 & 131 & 56 & 75 \\
\hline x & $13,2 \pm 3,3$ & $3,2 \pm 2,5$ & $10,0 \pm 3,2$ & $16,4 \pm 8,1$ & $7,0 \pm 6,7$ & $9,4 \pm 2,5$ \\
\hline
\end{tabular}


Tabela 2 - Número médio de amebócitos circulantes em moluscos B. glabrata e B. tenagophila infectados por 10 miracídios de S. mansoni das linhagens BH e SJ (Grupo 2).

\begin{tabular}{|c|c|c|c|c|c|c|}
\hline \multirow[b]{2}{*}{ Hora } & \multicolumn{3}{|c|}{ B. glabrata } & \multicolumn{3}{|c|}{ B. tenagophila } \\
\hline & $\begin{array}{l}\text { Amebócitos } \\
\text { totais }\end{array}$ & $\begin{array}{l}\text { Amebócitos } \\
\text { estrelados }\end{array}$ & $\begin{array}{c}\text { Amebócitos } \\
\text { não estrelados }\end{array}$ & $\begin{array}{l}\text { Amebócitos } \\
\text { totais }\end{array}$ & $\begin{array}{c}\text { Amebócitos } \\
\text { estrelados }\end{array}$ & $\begin{array}{c}\text { Amebócitos } \\
\text { não } \\
\text { estrelados }\end{array}$ \\
\hline $30^{\prime}$ & $18,2 \pm 23,0$ & $2,6 \pm 3,3$ & $15,4 \pm 19,5$ & $11,1 \pm 4,9$ & $3,3 \pm 2,0$ & $8,0 \pm 4,1$ \\
\hline 2 & $24,2 \pm 20,5$ & $6,2 \pm 4,2$ & $18,0 \pm 17,4$ & $15,0 \pm 8,8$ & $6,3 \pm 5,2$ & $8,6 \pm 4,2$ \\
\hline 3 & $10,2 \pm 5,0$ & $2,0 \pm 1,6$ & $8,2 \pm 4,6$ & - & - & - \\
\hline 4 & $9,3 \pm 3,4$ & $4,0 \pm \quad 2,4$ & $5,3 \pm 3,1$ & $11,3 \pm 4,9$ & $5,6 \pm 3,3$ & $5,6 \pm 2,1$ \\
\hline 5 & $12,1 \pm 6,5$ & $4,3 \pm 3,8$ & $8,0 \pm 4,0$ & - & - & - \\
\hline 6 & - & - & - & $15,0 \pm 13,8$ & $6,0 \pm 6,0$ & $9,3 \pm 8,1$ \\
\hline 8 & $16,0 \pm 7,1$ & $5,0 \pm 3,6$ & $11,0 \pm 4,4$ & $10,3 \pm 4,4$ & $4,0 \pm 3,9$ & $6,3 \pm 3,7$ \\
\hline 10 & - & - & - & $12,0 \pm 4,3$ & $4,1 \pm 3,2$ & $7,6 \pm 3,8$ \\
\hline 12 & - & - & - & $8,0 \pm 3,1$ & $3,6 \pm 2,4$ & $4,4 \pm \quad 4,4$ \\
\hline 14 & - & - & - & $18,6 \pm 14,1$ & $10,4 \pm 8,2$ & $8,1 \pm 8,1$ \\
\hline 16 & $12,1 \pm 4,7$ & $2,6 \pm 2,4$ & $9,6 \pm 4,3$ & $16,1 \pm 6,5$ & $7,0 \pm 2,5$ & $9,3 \pm 4,9$ \\
\hline 18 & - & - & - & $27,0 \pm 20,1$ & $16,0 \pm 13,5$ & $11,0 \pm 7,9$ \\
\hline 20 & - & - & - & $12,9 \pm 3,9$ & $4,0 \pm 2,8$ & $9,0 \pm 4,9$ \\
\hline 22 & - & - & - & $11,6 \pm 5,1$ & $5,0 \pm 2,3$ & $6,6 \pm 3,8$ \\
\hline 24 & $12,0 \pm 6,4$ & $3,6 \pm 1,5$ & $8,3 \pm 5,5$ & $12,6 \pm 4,9$ & $6,1 \pm 2,9$ & $6,4 \pm 3,3$ \\
\hline
\end{tabular}

Tabela 3 - Número médio de amebócitos circulantes em moluscos B. glabrata e B. tenagophila inoculados com tinta Nanquin (Grupo 3).

\begin{tabular}{|c|c|c|c|c|c|c|}
\hline \multirow[b]{2}{*}{ Hora } & \multicolumn{3}{|c|}{ B. glabrata } & \multicolumn{3}{|c|}{ B. tenagophila } \\
\hline & $\begin{array}{l}\text { Amebócitos } \\
\text { totais }\end{array}$ & $\begin{array}{l}\text { Amebócitos } \\
\text { estrelados }\end{array}$ & $\begin{array}{l}\text { Amebócitos } \\
\text { não estrelados }\end{array}$ & $\begin{array}{l}\text { Amebócitos } \\
\text { totais }\end{array}$ & $\begin{array}{l}\text { Amebócitos } \\
\text { estrelados }\end{array}$ & $\begin{array}{l}\text { Amebócitos } \\
\text { não } \\
\text { estrelados }\end{array}$ \\
\hline $30^{\prime}$ & $20,1 \pm 10,6$ & $6,0 \pm 8,1$ & $14,0 \pm 5,3$ & $28,0 \pm 11,1$ & $7,0 \pm 10,6$ & $21,0 \pm 5,9$ \\
\hline 2 & $43,2 \pm 14,3$ & $12,3 \pm 11,8$ & $31,0 \pm 12,6$ & $38,3 \pm 14,2$ & $6,6 \pm 10,6$ & $32,0 \pm 11,5$ \\
\hline 4 & $38,3 \pm 10,8$ & $12,6 \pm 9,3$ & $26,0 \pm 6,4$ & $36,3 \pm 12,8$ & $2,1 \pm 2,3$ & $34,1 \pm 34,1$ \\
\hline 6 & $17,0 \pm 11,8$ & $4,5 \pm 4,1$ & $12,3 \pm 16,7$ & $48,3 \pm 15,8$ & $15,1 \pm 16,5$ & $33,1 \pm 7,1$ \\
\hline 8 & $16,6 \pm 18,7$ & $4,1 \pm \quad 5,1$ & $12,4 \pm 4,2$ & $38,4 \pm 9,0$ & $5,1 \pm 5,4$ & $33,3 \pm 5,4$ \\
\hline 10 & - & - & - & $29,0 \pm 7,3$ & $9,1 \pm 7,8$ & $19,8 \pm 7,9$ \\
\hline 12 & $22,1 \pm 11,2$ & $7,1 \pm 6,4$ & $15,0 \pm 6,4$ & $27,4 \pm 8,4$ & $9,8 \pm 6,2$ & $17,6 \pm 6,4$ \\
\hline 14 & $19,0 \pm 13,4$ & $9,3 \pm 8,5$ & $10,0 \pm 6,8$ & $32,0 \pm 17,8$ & $2,4 \pm 2,3$ & $29,3 \pm 17,3$ \\
\hline 16 & $15,4 \pm 6,4$ & $2,2 \pm 1,5$ & $13,2 \pm 5,8$ & $39,0 \pm 8,0$ & $2,6 \pm 1,9$ & $36,4 \pm 9,1$ \\
\hline 18 & $14,6 \pm 7,5$ & $2,6 \pm 2,2$ & $12,0 \pm 6,4$ & $22,5 \pm 10,9$ & $2,4 \pm \quad 0,7$ & $20,1 \pm 11,2$ \\
\hline 20 & - & - & - & $19,3 \pm 4,3$ & $5,3 \pm 4,2$ & $14,0 \pm 4,4$ \\
\hline 22 & $24,0 \pm 11,7$ & $10,0 \pm 7,7$ & $14,0 \pm 5,6$ & $20,0 \pm 7,6$ & $6,0 \pm 5,3$ & $14,1 \pm 5,6$ \\
\hline 24 & $22,0 \pm 11,8$ & $4,0 \pm 3,9$ & $18,1 \pm 9,7$ & $27,2 \pm 9,6$ & $10,6 \pm 5,2$ & $16,6 \pm 13,5$ \\
\hline
\end{tabular}

b) Moluscos inoculados com tinta Nanquim (Tabela 3).

Em B. glabrata observou-se aumento inicial de amebócitos totais devido, principalmente, aos "não estrelados", lembrando o tipo de reação observada quando os moluscos foram infectados por S. manso$n i$, sendo que no caso da inoculação por tinta Nanquim o aumento inicial dos amebócitos prolongouse por mais duas horas. Em B. tenagophila observou-se, dos $30 \mathrm{~min}$, às $8 \mathrm{~h}$ e às $16 \mathrm{~h}$ aumento dos amebócitos totais devido aos "não estrelados".

c) Moluscos que sofreram injeção simulada (Tabela 4).
Neste grupo, em ambas as espécies de moluscos, houve aumento inicial de amebócitos totais devido, principalmente, aos amebócitos "não estrelados".

d) Moluscos com fratura da concha (Tabela 5).

Nas duas espécies estudadas não houve alterações significativas no número médio de amebócitos circulantes.

\section{Avaliação Histopatológica das Reações Teciduais}

Em B. glabrata observou-se um baixo índice de reação amebocitária em torno da larva, principal- 
Tabela 4 - Número médio de amebócitos circulantes em moluscos B. glabrata e B. tenagophila que sofreram injeção simulada (Grupo 4).

\begin{tabular}{|c|c|c|c|c|c|c|}
\hline \multirow[b]{2}{*}{ Hora } & \multicolumn{3}{|c|}{ B. glabrata } & \multicolumn{3}{|c|}{ B. tenagophila } \\
\hline & $\begin{array}{c}\text { Amebócitos } \\
\text { totais }\end{array}$ & $\begin{array}{l}\text { Amebócitos } \\
\text { estrelados }\end{array}$ & $\begin{array}{c}\text { Amebócitos } \\
\text { não estrelados }\end{array}$ & $\begin{array}{l}\text { Amebócitos } \\
\text { totais }\end{array}$ & $\begin{array}{l}\text { Amebócitos } \\
\text { estrelados }\end{array}$ & $\begin{array}{c}\text { Amebócitos } \\
\text { não } \\
\text { estrelados }\end{array}$ \\
\hline $30^{\prime}$ & $29,2 \pm 14,1$ & $11,5 \pm 13,0$ & $18,0 \pm 6,5$ & $62,4 \pm 11,2$ & $7,0 \pm \quad 4,7$ & $55,6 \pm 10,2$ \\
\hline 2 & $19,0 \pm 8,3$ & $9,3 \pm 6,9$ & $9,6 \pm 3,0$ & $46,0 \pm 12,1$ & $3,1 \pm 1,8$ & $42,6 \pm 13,0$ \\
\hline 4 & $25,0 \pm 9,7$ & $8,4 \pm 6,3$ & $16,4 \pm 11,9$ & $32,6 \pm 9,5$ & $4,0 \pm 2,0$ & $28,6 \pm 10,3$ \\
\hline 6 & $11,0 \pm 3,4$ & $4,1 \pm 3,2$ & $6,6 \pm 3,2$ & $31,6 \pm 8,2$ & $5,5 \pm \quad 4,4$ & $26,1 \pm 8,3$ \\
\hline 8 & $18,0 \pm 8,3$ & $7,0 \pm 6,3$ & $11,0 \pm 4,7$ & $32,0 \pm 16,2$ & $10,6 \pm 10,9$ & $21,4 \pm 9,9$ \\
\hline 10 & $12,3 \pm 8,3$ & $5,5 \pm \quad 5,8$ & $7,0 \pm 2,7$ & $26,5 \pm 8,4$ & $8,0 \pm 7,9$ & $18,5 \pm 6,9$ \\
\hline 11 & $20,1 \pm 4,2$ & $9,4 \pm \quad 5,6$ & $11,0 \pm 2,9$ & - & - & - \\
\hline 12 & $18,6 \pm 8,6$ & $6,0 \pm 3,6$ & $13,0 \pm 7,5$ & $22,0 \pm 7,9$ & $5,5 \pm 6,1$ & $16,5 \pm 5,7$ \\
\hline 14 & $18,4 \pm 6,1$ & $2,5 \pm 1,3$ & $16,0 \pm 6,7$ & $28,2 \pm 14,6$ & $2,6 \pm 3,4$ & $25,5 \pm 11,9$ \\
\hline 16 & $16,0 \pm 5,4$ & $4,1 \pm 3,0$ & $12,0 \pm 5,9$ & $34,0 \pm 9,7$ & $4,0 \pm 8,4$ & $30,0 \pm 7,5$ \\
\hline 18 & $11,4 \pm 6,6$ & $2,0 \pm 2,3$ & $9,4 \pm 4,8$ & $29,3 \pm 9,2$ & $1,5 \pm 1,8$ & $28,0 \pm 8,3$ \\
\hline 20 & $16,0 \pm 10,7$ & $5,0 \pm \quad 4,9$ & $11,0 \pm 4,4$ & $28,0 \pm 18,4$ & $2,3 \pm 2,6$ & $25,4 \pm 16,3$ \\
\hline 22 & $14,0 \pm 4,8$ & $2,5 \pm 1,5$ & $11,5 \pm 3,7$ & $17,0 \pm 11,7$ & $3,4 \pm 5,5$ & $13,6 \pm 8,7$ \\
\hline 24 & $14,0 \pm 8,4$ & $4,2 \pm 2,0$ & $10,0 \pm 7,5$ & $28,1 \pm 13,3$ & $9,4 \pm 6,1$ & $19,1 \pm 10,8$ \\
\hline
\end{tabular}

Tabela 5 - Número médio de amebócitos circulantes em moluscos B. glabrata e B. tenagophila com fratura da concha (Grupo 5).

\begin{tabular}{|c|c|c|c|c|c|c|}
\hline \multirow[b]{2}{*}{ Hora } & \multicolumn{3}{|c|}{ B. glabrata } & \multicolumn{3}{|c|}{ B. tenagophila } \\
\hline & $\begin{array}{c}\text { Amebócitos } \\
\text { totais }\end{array}$ & $\begin{array}{l}\text { Amebócitos } \\
\text { estrelados }\end{array}$ & $\begin{array}{c}\text { Amebócitos } \\
\text { não estrelados }\end{array}$ & $\begin{array}{l}\text { Amebócitos } \\
\text { totais }\end{array}$ & $\begin{array}{l}\text { Amebócitos } \\
\text { estrelados }\end{array}$ & $\begin{array}{c}\text { Amebócitos } \\
\text { não } \\
\text { estrelados }\end{array}$ \\
\hline $30^{\prime}$ & $11,3 \pm 5,7$ & $4,3 \pm 3,3$ & $7,0 \pm 4,1$ & $14,1 \pm 4,3$ & $3,6 \pm 2,5$ & $10,6 \pm 4,8$ \\
\hline 2 & $12,6 \pm 7,2$ & $6,0 \pm 4,1$ & $6,5 \pm 4,5$ & $16,3 \pm 9,8$ & $6,0 \pm 5,7$ & $10,6 \pm 5,4$ \\
\hline 4 & $13,0 \pm 5,3$ & $5,0 \pm 3,7$ & $8,0 \pm 2,8$ & $23,1 \pm 11,1$ & $6,0 \pm 3,8$ & $17,3 \pm 12,3$ \\
\hline 5 & $14,3 \pm 7,8$ & $6,0 \pm 3,7$ & $8,5 \pm 5,3$ & - & - & - \\
\hline 6 & $10,6 \pm 2,4$ & $5,2 \pm 2,4$ & $5,4 \pm \quad 0,9$ & $19,4 \pm 15,3$ & $8,6 \pm 9,3$ & $11,0 \pm 7,2$ \\
\hline 7 & $13,0 \pm 5,1$ & $4,4 \pm \quad 4,0$ & $8,5 \pm 1,7$ & - & - & - \\
\hline 8 & $12,5 \pm 7,4$ & $4,0 \pm 3,0$ & $8,6 \pm 5,9$ & $21,4 \pm 12,3$ & $10,0 \pm 8,8$ & $12,0 \pm 7,8$ \\
\hline 9 & $12,4 \pm \quad 6,8$ & $5,6 \pm 5,6$ & $7,0 \pm 3,0$ & - & - & - \\
\hline 10 & $12,1 \pm 6,1$ & $3,1 \pm 3,4$ & $9,0 \pm \quad 5,4$ & $13,6 \pm 6,1$ & $3,5 \pm 2,8$ & $10,2 \pm 4,4$ \\
\hline 11 & $19,5 \pm 18,0$ & $8,0 \pm 12,9$ & $11,5 \pm 6,2$ & - & - & - \\
\hline 12 & $17,0 \pm 5,1$ & $6,4 \pm 2,1$ & $10,4 \pm 3,8$ & $24,0 \pm 7,2$ & $14,2 \pm 9,0$ & $10,0 \pm 5,0$ \\
\hline 13 & $18,0 \pm 10,4$ & $5,0 \pm 3,1$ & $13,0 \pm 7,5$ & - & - & - \\
\hline 14 & $14,1 \pm 5,5$ & $3,4 \pm \quad 1,7$ & $11,0 \pm 4,2$ & $21,0 \pm 9,3$ & $8,3 \pm 4,0$ & $12,7 \pm 7,1$ \\
\hline 15 & $20,1 \pm 11,8$ & $6,5 \pm 6,0$ & $13,6 \pm 6,3$ & - & - & - \\
\hline 16 & $17,5 \pm 11,4$ & $8,6 \pm 10,5$ & $9,0 \pm 1,6$ & $18,0 \pm 5,6$ & $9,0 \pm 5,9$ & $9,3 \pm 4,3$ \\
\hline 17 & $19,0 \pm 12,9$ & $8,4 \pm 10,0$ & $11,0 \pm 5,5$ & - & - & - \\
\hline 18 & $22,0 \pm 9,2$ & $7,0 \pm 4,2$ & $15,0 \pm 6,1$ & $17,1 \pm 7,7$ & $7,4 \pm 4,7$ & $10,0 \pm 5,1$ \\
\hline 19 & $14,5 \pm 9,3$ & $3,6 \pm 2,7$ & $11,0 \pm 7,9$ & - & - & - \\
\hline 20 & $23,0 \pm 15,6$ & $9,2 \pm 7,7$ & $13,6 \pm 9,5$ & $15,3 \pm 8,3$ & $7,1 \pm 5,7$ & $8,1 \pm 2,9$ \\
\hline 21 & $25,6 \pm 12,1$ & $10,4 \pm 9,9$ & $15,3 \pm 6,6$ & - & - & - \\
\hline 22 & $22,0 \pm 19,8$ & $7,2 \pm 8,5$ & $15,0 \pm 11,6$ & $12,4 \pm 4,3$ & $4,0 \pm 4,2$ & $8,4 \pm 3,4$ \\
\hline 23 & $13,6 \pm 7,8$ & $4,5 \pm 2,5$ & $9,5 \pm 6,4$ & - & - & - \\
\hline 24 & $17,4 \pm 11,0$ & $7,0 \pm 6,9$ & $10,6 \pm 4,9$ & $19,0 \pm 6,2$ & $7,1 \pm 4,5$ & $11,6 \pm 5,5$ \\
\hline
\end{tabular}

mente nos intervalos de 18 e $24 \mathrm{~h}$, quando verificaram-se miracídios e esporocistos primários íntegros, isolados do tecido adjacente (Fig. 1). Na maioria dos cortes observou-se ausência de reação amebocitária. Excepcionalmente, nos intervalos de 30 min e $2 \mathrm{~h}$, foram encontrados alguns raros casos de reação amebocitária, mas predominavam, no mesmo corte, miracídios livres de qualquer reação tecidual (Fig. 2). Já em B. tenagophila foi observada a existência de reação amebocitária intensa nos intervalos de 30 min e $2 \mathrm{~h}$ (Fig. 3). Às 18 horas observou-se uma intensa camada de amebócitos cir- 


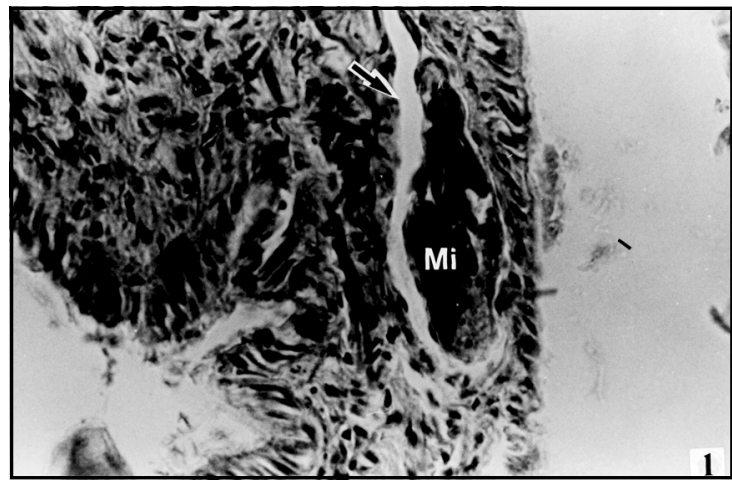

Figura 1 - Corte histológico de B. glabrata 24 h após infecção por $S$. mansoni. Ausência de reação amebocitária (seta) em torno da larva.

Tricrômico de Gomori, X640.

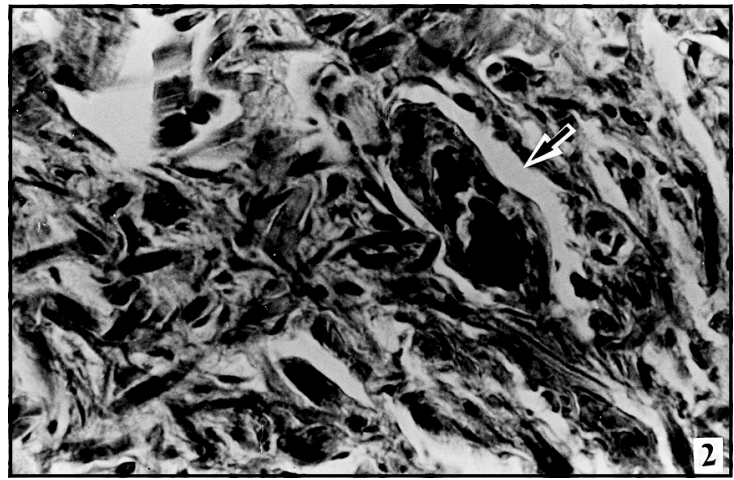

Figura 2 - Corte histológico de B. glabrata $24 \mathrm{~h}$ após infecção por $S$. mansoni. Ausência quase total de reação amebocitária (seta) em torno do miracídio (Mi).

Tricrômico de Gomori, X640

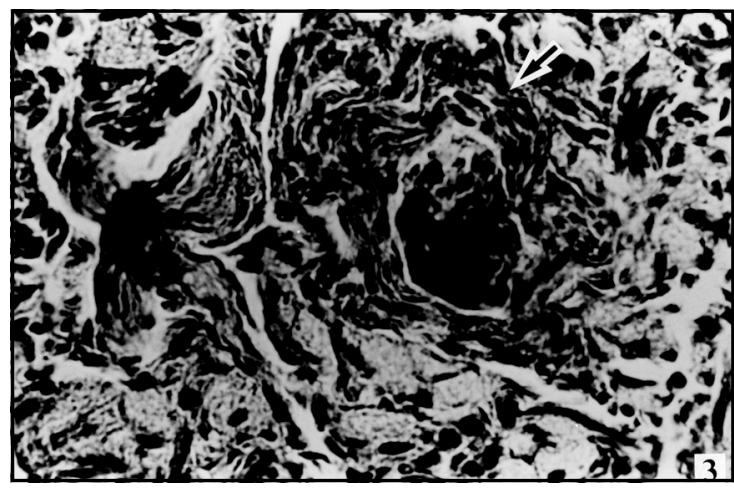

Figura 3 - Corte histológico de B. tenagophila 2 h após infecção por $S$. mansoni. Intensa reação amebocitária (seta), contendo múltiplas camadas de células em torno da larva. Tricrômico de Gomori, X640.

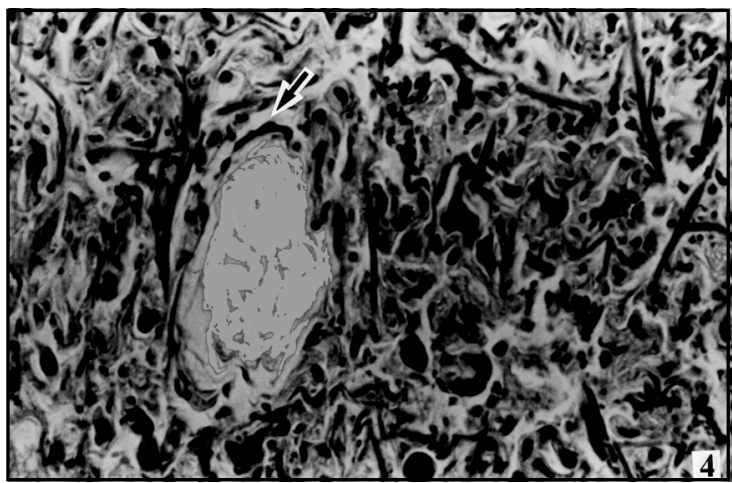

Figura 4 - Corte histológico de B. tenagophila 18 h após infecção por S. mansoni. Intensa reação amebocitária (seta), formando uma capa de amebócitos em torno da larva. Tricrômico de Gomori, X640.

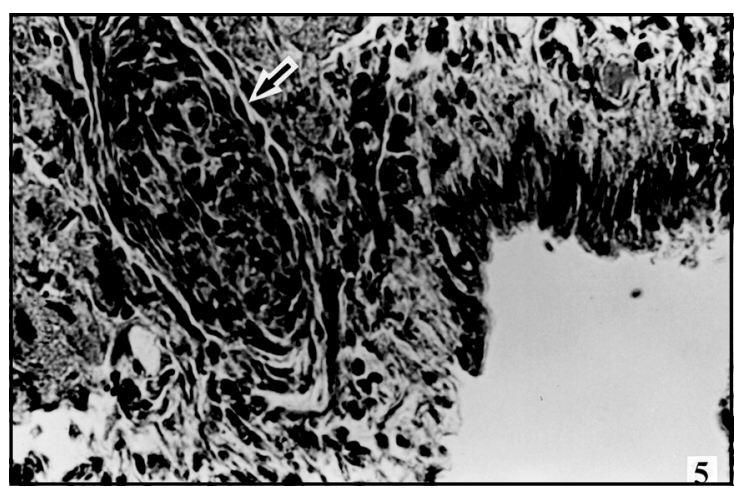

Figura 5 - Corte histológico de B. tenagophila 24 h após infecção por $S$. mansoni. Intensa reação amebocitária (seta) em torno da larva, que apresenta sinais evidentes de degeneração.

Tricrômico de Gomori, X640.

cundando as larvas (Fig. 4). No intervalo de $24 \mathrm{~h}$ foi muito raro o encontro de esporocistos íntegros, com possibilidade de sobrevivência. A maioria dos esporocistos apresentavam núcleos picnóticos e células em degeneração (Fig. 5).

\section{Morfologia dos Amebócitos Circulantes}

Verificou-se que a morfologia dos amebócitos circulantes de ambas as espécies de moluscos variou no tempo após o contato com a lâmina microscópica. Num primeiro momento, foram encontrados células arredondadas, sem prolongamentos citoplasmáticos. Com o passar dos minutos, tais prolongamentos surgiam conferindo à célula o aspecto "estrelado". Aos 25 a 35 min. de contato com a lâmina, observou-se que a maioria dos amebócitos haviam se 
espraiado, de modo semelhante aos macrófagos de vertebrados, sendo que poucos amebócitos "não estrelados" foram encontrados nessa ocasião. Observou-se também células pequenas que podem corresponder ao terceiro tipo de amebócito descrito na literatura.

\section{DISCUSSÃO}

Nos moluscos infectados por S. mansoni, o aumento brusco do número de amebócitos circulantes ocorrido em B. glabrata, chamado por alguns autores de "leucocitose", é um fenômeno resultante da infecção parasitária. Stumpf e Gilbertson ${ }^{14}$ (1978) observaram um aumento do número de amebócitos circulantes em B. glabrata suscetível, 2 h após à infecção pelo $S$. mansoni. Granath e Yoshino ${ }^{6}$ (1984) verificaram em $B$. glabrata da linhagem PR albina suscetível, aumento precoce de amebócitos circulantes e, após uma hora de infecção, uma diminuição brusca, atingindo o valor inicial por volta das $24 \mathrm{~h}$. Foram obtidos resultados semelhantes a estes em $B$. glabrata infectadas por S. mansoni. O fato de não ter havido variações significativas do número de amebócitos "estrelados", células que exercem função de fagocitose, parece explicar a maior suscetibilidade desses moluscos à infecção pelo $S$. mansoni. Em B. tenagophila, obteve-se aumento tardio de amebócitos circulantes sendo que as células responsáveis por esse aumento foram os amebócitos "estrelados". Tal aumento pode ter ocorrido devido à requisição precoce dessas células para o combate aos esporocistos (Loker e Bayne ${ }^{8}$, 1982). O perfil de variação dos amebócitos encontrados em B. tenagophi$l a$, sugere especificidade da resposta ao parasita, se comparado aos demais estímulos observados nas duas espécies de moluscos.

Nos moluscos inoculados com tinta Nanquim, a semelhança encontrada entre os perfis de variação dos amebócitos circulantes em ambas as espécies, sugere a não existência de especificidade da reação. Em B. tenagophila a reação observada à tinta Nanquim foi diferente da observada após a infecção por S. mansoni, pois, neste caso, o aumento do número de amebócitos circulantes totais deveu-se, principalmente, aos amebócitos "estrelados". A tinta Nanquim pode ser considerada inerte para os moluscos e foi usada como controle da infecção pelo S. mansoni, comparando-se o comportamento dos amebócitos ocorrido frente à matéria viva (parasita) com o ocorrido frente à matéria inerte (tinta Nanquim).

As oscilações do número de amebócitos encontradas nos moluscos submetidos à injeção simula- da parecem ter ocorrido simplesmente devido a cicatrização dos ferimentos provocados pela agulha de injeção.

No grupo submetido à fratura da concha não houve alterações significativas do número de amebócitos circulantes. Sabe-se que os amebócitos são responsáveis pelo transporte de cálcio, visando ao reparo tecidual (Ratcliffe ${ }^{11}$, 1985; Wagge ${ }^{15}$, 1951; Wagge e Mittler ${ }^{16}$, 1953).

Os resultados encontrados levaram à conclusão de duas hipóteses: 1) Os amebócitos circulantes não sofreram estímulo para que seu número aumentasse; ou 2) $\mathrm{O}$ aumento e conseqüentemente o deslocamento para a região da fratura, ocorreram após o período analisado no experimento. As oscilações observadas podem ter tido relação com a requisição das células para o transporte de cálcio. Nesse caso, como houve grande oscilação nos dois tipos de células, é difícil afirmar que somente as "não estreladas" foram requisitadas.

Os resultados da avaliação histopatológica evidenciam que já no primeiro dia de infecção pôde-se encontrar reações amebocitárias em torno das larvas. Foi observada a ocorrência de típicas reações granulomatosas, principalmente em B. tenagophila. Resultados semelhantes foram obtidos por Guaraldo e col. ${ }^{7}$ (1981) quando, ao estudarem a evolução dos esporocistos de $S$. mansoni em B. glabrata e B. tenagophila, nos intervalos entre a primeira e a oitava semanas após a infecção, observaram reações granulomatosas amebocitárias circundando as larvas, sobretudo em B. tenogophila, havendo predomínio de esporocistos degenerados. Correlacionando os perfis de variação cinética dos amebócitos circulantes com a avaliação histopatológica pode-se destacar alguns aspectos interessantes: I) Em B. tenagophila foram obtidos inicialmente diminuição do número de amebócitos, a qual atribui-se a uma possível migração dessas células para os tecidos visando ao combate aos esporocistos. Este fato ficou evidenciado pelas reações teciduais observadas nos períodos de 30 min e $2 \mathrm{~h}$ após a infecção. II) Curiosamente, no período de $18 \mathrm{~h}$ após à infecção em $B$. tenagophila observou-se, ao mesmo tempo, um pico de amebócitos circulantes, sobretudo "estrelados", e uma intensa reação amebocitária em torno da larva. Provavelmente o estímulo da APO (órgão produtor de amebócitos) seja contínuo a partir do contato inicial das células requisitadas para os tecidos, com os esporocistos. Ao mesmo tempo que ocorreria uma estimulação do APO, provocando a produção de amebócitos que reagem ao parasita, deveria ocorrer também o retorno dos amebócitos "estrelados" à circu- 
lação, o que tornaria mais eficiente a resposta imune do molusco à infecção. Na verdade não devem se tratar de fenômenos isolados, pois no decorrer da infecção o APO é estimulado a produzir mais células, provavelmente mais amebócitos "estrelados", que se dirigiriam à circulação e ao mesmo tempo continuaria ocorrendo a reação no tecido e, havendo a necessidade de mais células, o APO seria novamente estimulado, e assim sucessivamente. III) Em $B$. glabrata infectadas por $S$. mansoni não se observou correlação significativa entre a variação do número de amebócitos circulantes e a reação tecidual. Nos períodos de 30 min e de $2 \mathrm{~h}$ após à infecção, quando ocorreu o pico de amebócitos, observou-se, na maioria dos cortes, a presença de discreta reação amebocitária e pouquíssimos casos de reação intensa. Nos períodos de 10, 18 e $24 \mathrm{~h}$, verificou-se ausência de reação amebocitária em torno da larva, períodos estes em que foi observada diminuição gradativa do número de amebócitos, atingindo valores semelhantes aos obtidos na ausência da infecção.

As alterações morfológicas dos amebócitos observadas parecem ter semelhança às quatro fases descritas por Morona e col. ${ }^{9}$ (1984) que, segundo os autores, poderiam representar os estágios ontogenéticos dos "granulócitos" em seu papel de defesa celular contra corpos estranhos. Não há evidências de que uma célula se transforme em outra, ou seja, que o amebócito "não estrelado" se transforme em "estrelado", porém os presentes resultados sugerem essa possibilidade.

\section{REFERÊNCIAS BIBLIOGRÁFICAS}

1. ABDUL-SALAM, J.M. \& MICHELSON, E.H. Biomphalaria glabrata amebocytes: effects of Schistosoma mansoni infection on in vitro phagocytosis. J. Invertebr. Pathol., 35: 241-8, 1980.

2. AMEN, R.I.; BAGGEN, J.M.C.; BEZEMER, P.D.; JONG-BRINK, M. Modulation of the activity of the internal defence system of the pond snail Lymnaea stagnalis by the avian Schistosoma trichobilharzia ocellata. Parasitology, 104: 33-40, 1992.

3. BAYNE, C.J.; BUCKLEY, P.M.; DE WAN, P.C. Citotoxity of hemocytes from susceptible snail hosts for sporocysts in plasma from resistant Biomphalaria glabrata. Exp. Parasitol., 50: 409-16, 1980.

4. CHENG, T.C.; RODRICK, G.E.; FOLEY, D.A., KOEHLER, S.A. Release of lysosyme from hemolymph cells of Mercenaria mercenaria during phagocytosis. J. Invertebr. Pathol., 25: 261-5, 1975.
Comparando os resultados obtidos pode-se concluir que esses moluscos apresentam comportamentos amebocitários diferentes frente aos diversos estímulos utilizados, sobretudo no que se refere à infecção pelo $S$. mansoni, sugerindo especificidade ao parasita. Quando submetidos à infecção pelo $S$. mansoni, moluscos B. glabrata apresentaram aumento imediato dos amebócitos circulantes, enquanto que moluscos B. tenagophila apresentaram aumento tardio, sugerindo uma mobilização prévia para os tecidos. Tais resultados foram confirmados pela avaliação histopatológica, mostrando grande incidência de reações amebocitárias intensas, já nos períodos iniciais, em torno das larvas em B. tenagophila. Às 24 $\mathrm{h}$ foram observados vários esporocistos fragmentados e pouquíssimos esporocistos inteiros, na sua maioria inviáveis. O mesmo não ocorreu em $B$. glabrata, que apresentou baixa incidência de reações amebocitárias em torno das larvas no período inicial. Nesta espécie, no período de 24 h, observou-se ausência de reação com a presença de esporocistos viáveis.

Em conclusão, observando-se em conjunto os quatro tipos de estímulo aos quais foram submetidos os moluscos, verifica-se que somente no caso da infecção por $S$. mansoni em B. tenagophila houve mobilização de amebócitos "estrelados". Exatamente esta espécie de molusco é a que apresenta maior resistência à infecção, o que sugere especificidade da reação ao parasita.

5. CHENG, T.C. \& BUTLER, M.S. Experimentally induced elevations in acid phosphatase activity in the hemolymph of Biomphalaria glabrata (Mollusca). J. Invertebr. Pathol., 34: 119-29, 1979.

6- GRANATH, W.O. \& YOSHINO, T.P. Schistosoma mansoni: passive transfer of resistance by serum in the vector snail Biomphalaria glabrata. Exp. Parasitol., 58: 188-93, 1984.

7. GUARALDO, A.M.A.; MAGALHÃES, L.A.; RANGEL, H.A. ; PAREJA, G. Evolução dos esporocistos de Schistosoma mansoni Sambon, 1907 em Biomphalaria glabrata (Say, 1818) e Biomphalaria tenagophila (D' Orbigny, 1835). Rev. Saúde Pública, 15: 436-48, 1981.

8. LOKER, E.S. \& BAYNE, C.J. In vitro encounters between Schistosoma mansoni primary sporocysts and hem olymph components of susceptible and resistant strains of Biomphalaria glabrata. Am. J. Trop. Med. Hyg., 31: 9991005, 1982. 
9. MORONA, D.; JOURDANE, J.; AESCHLIMANN, A. Étude de l'evolution in vitro des granulocytes de l'hemolymphe de Biomphalaria glabrata (Gastropoda, Planorbidae). Étude au microscope electronique. Ann. Parasitol. Hum. Comp., 59: 467-75, 1984.

10. PARAENSE, W. L. \& CORRÊA, L. R. Sobre a ocorrência de duas raças biológicas do Schistsosoma mansoni no Brasil. Ciên. Cult., 15: 245-6, 1963.

11. RATCLIFF, N.A. Invertebrate immunity. A primer for the non-specialist. Immunol. Letters, 10: 253-70, 1985.

12. SANTANA, J.V.; MAGALHÃES, L.A.; RANGEL, H.A. Quantificação da atividade fagocitária de amebócitos de moluscos Biomphalaria glabrata livres de infecção e infectados por Schistosoma mamsoni. In: Congresso da Sociedade Brasileira de Medicina Tropical, 21 ${ }^{\circ}$, São
Paulo, 1985. Anais. São Paulo, C. Baliero Editora, 1985. Resumo ${ }^{\circ} 58$.

13. SMINIA, T. \& VAN DER KNAAP, W.P.W. Cells and molecules in molluscan immunology. Dev. Comp. Immunol., 11: 17-28, 1987.

14. STUMPF, J.L. \& GILBERTSON, D.E. Hemocytes of Biomphalaria glabrata. Factor affecting variability. $J$. Invertebr. Pathol., 32: 177-81, 1978.

15. WEGGE, L.E. The activity of amoebocytes and of alkaline phosphatase during the regeneration of wall of the snail Helix aspersa. Q. J. Microsc. Sci., 92: 307-21, 1951.

16. WEGGE, L.E. \& MITTLER, T. Shell recognition in some Brithish molluscs. Nature, 171: 528-9, 1953. 